\title{
Artiga especial
}

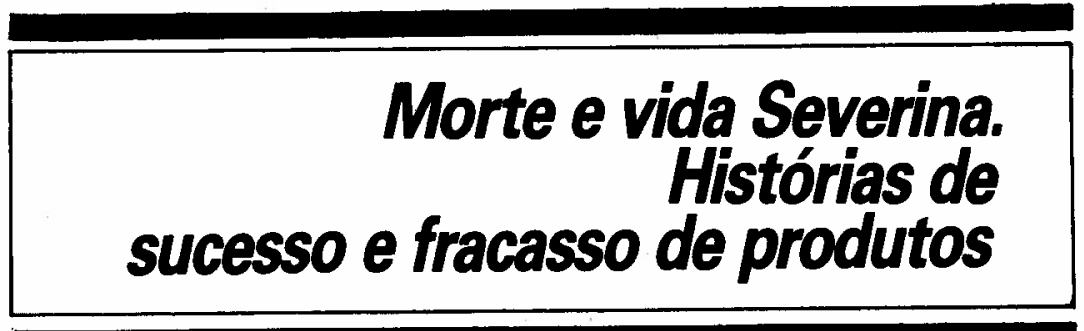

Julio Cesar Ribeiro
Publicitário. Planejador de Marketing e presidente da Talent Comunicacão

Ltda.

O meu amigo estava perturbado; nunca o vira assim antes. Bateu na minha mesa com um volumoso relatório e disse: - "Eu quero que você leia este plano. Me diga o que é que está errado nele."

Quando vi o marketing plan, fiquei impressionado. Começando pela qualidade da encadernação. Uma capa cinza fosca, amarrada por um espiral preto, grosso. Em letras futura, corpo 10 , apenas uma frase: "Tasty: uma nova idéia em maionese'". Oitenta páginas de texto.

O mercado de maionese é grande, dominado pela Hellman's, marca da Refinações de Milho Brasil, que possui $45 \%$ de participação, seguida pela Gourmet, com $25 \%$, e que apresentou um crescimento neste último ano de, aproximadamente, $34 \%$. As donas-de-casa foram aos poucos substituindo a maionese caseira pela industrializada, a ponto de a maioria delas, hoje, não ser capaz de preparar maionese em casa. Contudo, esperam que a maionese industrializada aproxime-se 0 máximo possível da caseira, em termos de ingredientes e em termos de imagem. $O$ público-alvo é constituido por mulheres casadas, das áreas urbanas, na faixa etária entre 25 e 55 anos, sendo que neste grupo o principal veículo de informação é a televisão.
As informações estavam todas no plano. Gráficos, tabelas, previsões de vendas mês a mês, tudo. Os testes cegos demonstravam que o sabor levemente picante de Tasty era preferido ao de Hellman's por $18 \%$ das donas-de-casa pesquisadas. A embalagem também foi preferida por ter a boca mais larga (facilita a entrada da colher). Em decorrência destes fatos, recomendava-se desenvolver uma campanha de comunicação que enfatizasse a fórmula caseira do produto (ovos frescos, óleo de milho, limão etc.) e o sabor picante.

Com tanta informação e com uma linha de raciocínio tão lógica, não tinha como errar. "E vamos. nos preparar para um estrondoso sucesso de vendas"; terminava com esta frase o plano. A Tasty foi um fracasso total. Lançada no mercado-teste de Curitiba, encalhou nas prateleiras, apodreceu e acabou sendo engavetada com as justificativas de sempre, possivelmente apresentadas em outro relatório de capa cinza, escritas de modo a não colocar a pele do meu amigo em risco.

Apesar da bela encadernação, das 80 páginas de informação, gráficos, textos, teste cego etc; quase tudo nesse plano estava errado. Os números? Não. $\mathrm{O}$ que estava errado era a interpretação dessas informações.

A maionese Hellman's é líder de mercado; as donas-de-casa querem uma maionese com feições caseiras; o público alvo é realmente constituído por mulheres casadas etc. Isto tudo está certo. $O$ que não está certo é concluir que se pode conquistar $5 \%$ do mercado no primeiro ano, com uma maionese com a mesma cara da Hellman's, vendida nos mesmos pontos de venda, ao mesmo preço e com uma campanha aśsemelhada. $O$ que $a$ maionese Tasty propôs, as donas-de-casa já têm. Não precisam mudar de marca.

Depois de muitos anos criando campanhas e fazendo planejamento estratégico para produtos de grandes corporações e depois de assistir ao fracasso ou à vitória de centenas deles, estou convencido de que a principal moléstia que faz produtos virarem "anjinhos" é a incapacidade ou o erro dos planejadores na interpretação da real finalidade da existência do produto no mercado.

Os planos de marketing estão cheios de soluções brilhantes para produtos que não são os que vão ser lançados, ou situações de mercado que não são aquelas em que o produto vai atuar quando lançado. Vejamos isto um pouco melhor: um produto só sobrevive no mercado se ele estiver resolvendo simultaneamente os problemas de todos os segmentos de marketing relacionados com a sua existência, ou seja: do fabricante, do revendedor, do consumidor e, na maioria dos casos, das pessoas que trabalham com os fabricantes e com os revendedores. Um exemplo recente: o boi a Cz\$240,00 a arroba resolve o problema do consumidor, dos frigorificos e dos açougues. Mas não resolve o problema do produtor. $\mathrm{O}$ resultado é que não existe carne.

Cansei de ver produtos que, mesmo vendendo bem, foram tirados de linha, por falta de margem para o produtor ou para o revendedor. Assisti a funerais de produtos eliminados, porque os volumes de vendas ficaram aquém da previsão, não porque o 
consumidor não comprasse, mas porque o tamanho do mercado fora superdimensionado no planejamento. Na França há o caso clássico de um sabonete cosmético à base de algas, que foi tirado de mercado porque durava demais. Seis meses em média. $O$ sabonete, embora tivesse uma consistência semelhante à dos demais produtos, durava demais porque as mulheres usavam-no apenas para lavar o rosto. Atendeu às necessidades do consumidor, mas não às do fabricante. Morreu.

Quando se planeja um novo produto, é fundamental determinar que benefícios a empresa espera obter com esse lançamento. $O$ mesmo acontece com o consumidor. Um fato óbvio, que muita gente esquece, é que ninguém compra produtos ou serviços. As pessoas compram as vantagens que podem tirar dos mesmos. Isto é o que estava errado no plano do meu amigo. Se as mulheres não precisam de um novo sabor de maionese, $o$ caminho do sucesso tem que ser procurado em termos de descobrir-se quais necessidades dessas mulheres uma nova maionese poderia preencher.

Uma das perguntas que eu sempre me faço é se as necessidades das pessoas têm de ser preenchidas a nivel de produto. Na maioria dos casos a resposta é não. As pessoas têm muito mais necessidades a nível psicológico, sensível, filosófico, social, existencial etc. do que meramente obter $5 \%$ a mais de espuma quando lavam roupa. É muito difícil produzir-se um produto de consumo realmente diferente, em termos de desempenho. Por outro lado, os produtos são, na maioria das vezes, uma ferramenta com a qual se realiza algo. Um relógio Cartier é mais do que um aparelho de marcar o tempo, é uma

ferramenta de produzir sensações. O mesmo é verdade para cigarros, bebidas, perfumes, automóveis e mesmo produtos mais prosaicos, como sabonetes, desodorantes ou xampus.

Durante muitos anos trabalhei com margarinas. A expansão do consumo desse produto no Brasil tem sido historicamente uma luta entre dois sentimentos: $o$ desejo da dona-de-casa em usar um produto mais barato do que a manteiga e o sentimento de culpa por estar oferecendo à família um produto que elas consideram inferior. Na medida em que essa sensação foi desaparecendo, aumentou o consumo de margarinas.

As pesquisas que temos desenvolvido demonstram que a preferência por determinada marca de margarina está muito mais ligada a apostos psicológicos de qualidade associados à marca do que a sabor. Em termos de sabor, pouca gente distingue uma margarina de outra. Já, "sensação de sabor" é outra coisa. Talvez a única real, na preferência entre margarinas.

Todo produto tem alguma coisa para oferecer. Fórmula para o sucesso não existe. Um bom caminho é começar o planejamento procurando conferir as carências do nosso consumidor, do nosso revendedor e da nossa empresa.

A partir daí, talvez se possa determinar o perfil de um produto que atenda a uma ou mais dessas necessidades. Talvez, a partir de um produto já existente, determinar qual a sua linha de força, ou seja, aquelas características que preencham efetivamente carências no seu universo de comercialização. Temos tido muito sucesso com produtos, trabalhando nessa linha. Se um dia eu tivesse que vender a maionese do meu amigo, eu iria investir muito tempo, procurando saber quais as sensações que estão envolvidas no ato de usar, comprar, fabricar e vender maionese. Juro que não faria um anúncio com o título "A surpresa que a sua família aguardava."

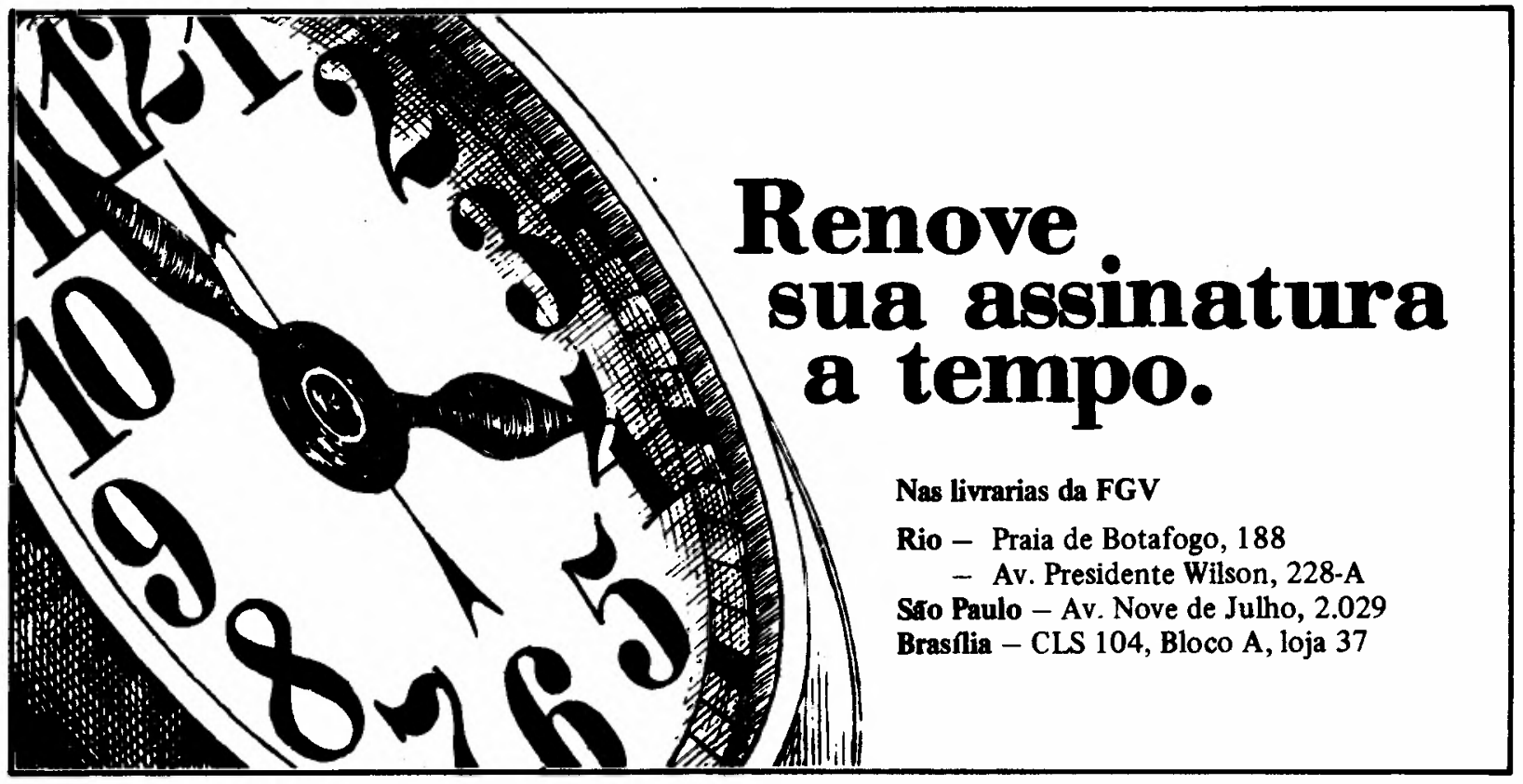

